\title{
Repensando o pluralismo: reforma do sistema de saúde e polarização política nos Estados Unidos
}

\author{
Rethinking pluralism: health care system reform and political polarization in the United States
}

\author{
André Luís Scantimburgo \\ Doutorando e Mestre em Relações Internacionais e \\ Desenvolvimento pelo Programa de Pós-Graduação em \\ Ciências Sociais da Unesp, campus de Marília \\ e-mail: scantimburgo@gmail.com

\section{Saulo de Castro Lima} \\ Universidade Federal de Santa Catarina/Universidade do \\ Estado de Santa Catarina \\ Professor do Departamento de Economia e Relações \\ Internacionais do Centro Sócio-Econômico da UFSC e \\ do Departamento de Economia do Centro de Ciências da \\ Administração e Sócio-econômicas da UDESC \\ e-mail: saulocastrol@yahoo.com.br
}

Recebido: 05/03/2013

Aceito: 31/07/2013
RESUMO O objetivo central deste artigo é elucidar a importância da tradição política pluralista dos Estados Unidos no debate sobre a reforma do sistema de saúde, tendo em vista o crescente processo de polarização desencadeado a partir de seu lançamento. $\mathrm{O}$ artigo está dividido em duas partes: na primeira são apresentadas as principais características de funcionamento do antigo sistema de saúde estadunidense, traçando um breve perfil e, também, apresentando os pontos de vista de democratas e republicanos em torno da proposta de reforma; na segunda parte, analisa-se o contexto de polarização política no qual se insere o debate entre as propostas, desenvolvido à luz da cultura pluralista presente na política dos Estados Unidos e estabelecendo a relação existente entre pluralismo, polarização e a reforma do sistema de saúde estadunidense.

PALAVRAS-CHAVE Reforma do sistema de saúde; Pluralismo político; Governo Obama; Polarização.

ABSTRACT The main goal of this paper is to clear the importance of the U.S.' pluralist political tradition in the discussion about the health care system reform, considering the growing polarization process triggered by its launch. The paper has two parts: at first, We present the main operating features of the old American health care system, tracing a brief profile and also presenting the republicans and democrats point of view about the reform; then, in the second part, we analyze the context of political polarization in which lies the debate among the proposals, developed in light of the pluralist culture in the U.S. politics and establishing the relation between pluralism, polarization and the health care system reform.

KEYWORDS Health care system reform; Political pluralism; Obama Administration; Polarization. 


\section{Introdução}

A crise econômica mundial que se espalhou a partir do estouro da bolha especulativa do setor imobiliário dos Estados Unidos em 2008 trouxe à tona ideias e discursos que o sistema financeiro internacional manteve em desuso ao longo do último quarto de século. A confiança na credibilidade do mercado financeiro (concebido como todo poderoso) tornou-se cada vez mais abalada, ao passo que conceitos como planejamento, estatização, Estado Nação e intervencionismo ressurgiram no vocabulário de economistas e cientistas políticos. Operadores do sistema financeiro, empresários, políticos e acadêmicos pregadores da infalibilidade do funcionamento livre e irrestrito dos mecanismos de mercado defrontaram-se com a crise de um sistema que, à imagem do que aconteceu em 1929, foi implodido a partir de suas contradições. A sequiência vertiginosa de quebras e falências desencadeadas a partir do estouro da bolha especulativa do mercado imobiliário estadunidense tratou de mostrar, ainda que de modo doloroso, que o credo nas virtudes do mercado livre e irrestrito havia alcançado seu limite, e que além de Von Hayek havia Keynes.

Como resposta à crise, mais uma vez assistiu-se a aplicação de uma série de medidas para reanimar as economias do centro dinâmico do capitalismo mundial e também da periferia do sistema. Em comum, essas medidas não foram pautadas pelo livre mercado, mas basicamente pela pronta intervenção direta do Estado no funcionamento de suas economias, contrastando com a política estritamente liberal de Coolidge $^{1}$ nos anos 1920, que culminou com a Crise de 1929 e, por sua vez, afastando a possibilidade de uma alternativa ainda baseada no laissez-faire como tentada pelo presidente Herbert Hoover ${ }^{2}$ no início da década de 1930. Dentre as medidas atuais, a compra de parte da gigante General Motors pelo governo dos Estados Unidos tornou-se um emblema da estatização inimaginável poucos anos atrás. As próprias recomendações do sempre ortodoxo Fundo Monetário Internacional para o setor bancário também foram na direção da estatização, bem como os pacotes de incentivos às economias nacionais que também se orientaram pela lógica da indução ou do controle estatal, reacenderam os debates acerca da mal resolvida questão sobre o lugar do Estado na economia. É nesse contexto crítico que se iniciou o

\footnotetext{
John Alvin Coolidge Jr., foi eleito vice presidente dos Estados Unidos em 1920 e assumiu a presidência após a morte de Warren G. Harding em 1923. Foi reeleito em 1924 pelo partido Republicano.

${ }^{2}$ Herbert Clarck Hoover, presidente republicano dos Estados Unidos entre 1929 e 1933.
}

mandato presidencial do democrata Barack Obama, em janeiro de 2009.

Vários foram os problemas enfrentados por Obama logo no início de seu mandato e que ainda persistem, sobretudo em âmbito externo: a questão da retirada das tropas militares do Iraque e Afeganistão; a situação da prisão de Guantánamo; a completa recuperação econômica; a recuperação da imagem desgastada dos EUA em várias partes do mundo, etc. Mas foi uma questão de política interna, em especial, que gerou maior discussão em seu primeiro ano de mandato: a reforma do sistema de saúde do país, foco desta análise.

$\mathrm{O}$ presente artigo está dividido em duas partes. $\mathrm{Na}$ primeira, são apresentadas as principais características de funcionamento do antigo sistema de saúde estadunidense, traçando um breve perfil. Nessa seção estão colocados também os pontos de vista dos democratas e republicanos em torno da proposta de reforma. Na segunda seção, o objetivo é analisar do contexto de polarização política existente no país e que alimenta o debate, trabalhado à luz da cultura pluralista presente na política dos Estados Unidos. Assim, pode-se estabelecer a relação existente entre pluralismo, polarização e a reforma do sistema de saúde.

Ainda que aprovada em 23 de março de 2010, a reforma do sistema de saúde dos Estados Unidos ainda pode ser considerada como um processo em curso. A disputa entre republicanos e democratas se estendeu também pelo período posterior a aprovação da lei que regulamenta o novo modus operandi do sistema de saúde devido a processos, julgamentos de inconstitucionalidade e ações na justiça. As circunstâncias peculiares que se apresentam nesta conjuntura tornam tarefa imperativa aos pesquisadores não apenas a compreensão de processos históricos acabados, mas a elaboração de hipóteses que sejam parte significativa de tal compreensão e que colaborem na construção do arcabouço de conhecimentos sobre esse momento histórico. É este o espírito e o motivo deste ensaio.

\section{Considerações sobre o Health Care}

O sistema de saúde dos Estados Unidos (Health Care) que vigorou até 2010 é amplamente questionado por seu custo benefício e pelo seu funcionamento controverso. De acordo com documento do Economic Policy Institute (EPI) ${ }^{3}$, a raiz do problema com o modelo é que o país apresenta o maior gasto anual

\footnotetext{
Disponível em: <http://www.epi.org>. Acesso em: 10 fev. 2011
} 
com saúde do mundo, mas está longe de oferecer o melhor sistema de saúde mundial à sua população (HACKER, 2007).

Uma peculiaridade do sistema de saúde estadunidense era a ausência da prestação direta do serviço público na maior parte dos casos, predominando a cobertura através de planos de saúde privados ou corporativos. Quem não pode pagar pela cobertura de plano de saúde ou não recebe cobertura pelo seu empregador, deve pagar suas despesas médicas com recursos próprios. Segundo dados da Organização Mundial de Saúde (OMS) para o ano de 2000 , cerca de $15 \%$ da população não contava com nenhum tipo de cobertura por plano, número que vem aumentando nos últimos anos. Considerando-se a população aproximada de 300 milhões de habitantes, chega-se a uma cifra de quase 45 milhões de habitantes sem qualquer tipo de acesso ao sistema. Não é por acaso que os gastos com saúde são freqüentemente apontados como responsáveis por grande parte das falências pessoais no país, tornando quase que compulsório o debate sobre um novo modelo de saúde, como atestou o presidente Obama em discurso oficial:

Pela primeira vez, quase todos os envolvidos nesse debate - pacientes, hospitais, médicos, enfermeiras, pequenas e grandes empresas, Democratas e Republicanos, até mesmo aqueles mais envolvidos no status quo - inclusas nossas companhias seguradoras- todos sabiam que finalmente algo precisava ser feito sobre o falido sistema de saúde da América. (The White House, 2010: 1, tradução nossa).

A situação descrita por Obama pode ser mais bem visualizada na passagem a seguir, extraída de publicação oficial da Organização Panamericana de Saúde e que apresenta uma boa síntese sobre o funcionamento da prestação do serviço de saúde nos Estados Unidos:

Os serviços de saúde são prestados em grande parte pelo setor privado. As seguradoras comerciais desempenham uma função importante no financiamento da assistência médica. A maior parte da cobertura de serviços de saúde se obtém por meio de uma terceira entidade pagadora, como um empregador ou o governo, que efetua os pagamentos, direta ou indiretamente aos provedores de serviços. Isto pode incluir os custos dos médicos, hospitais, laboratórios, farmácias, etc., segunda o tipo de seguro. (OPS, 2002: 11, tradução nossa).

Há casos em que o governo atua como provedor direto dos serviços de saúde: para militares e veteranos de guerra, presidiários, indígenas e nativos do
Alasca. Há, ainda, dois programas governamentais importantes, embora voltados para segmentos específicos da população, o Medicare e o Medicaid, ambos criados durante a década de 1960.

O Medicare consiste no atendimento médico e na medicação de idosos acima dos 65 anos de idade, portadores de insuficiências renais graves e portadores de certos tipos de deficiências, como a visual. Já o Medicaid é voltado para o atendimento de saúde de famílias de baixa renda, em conjunto com os governos estaduais. De acordo com pesquisa do Instituto Gallup (2009), cerca de $30 \%$ da população dos EUA recebe cobertura governamental para a saúde.

A insegurança no tocante à saúde é uma realidade constante para cada vez mais cidadãos estadunidenses. A elevação acelerada dos custos de saúde no país tem sido inversamente proporcional ao número de pessoas com renda estável. Tanto as pessoas que não tem cobertura como as que correm risco de perdê-la, ou mesmo pessoas com boa situação econômica que eventualmente tenham que arcar com os custos elevados da saúde podem experimentar tal insegurança. Essa possibilidade tornou-se maior após a crise econômica de 2008.

O simples fato de a reforma do sistema de saúde constar na agenda governamental do presidente Obama foi considerado um avanço, pois o tema permaneceu intocado por anos, desde a tentativa de reforma durante a primeira administração Clinton ${ }^{4}$. Por isso mesmo, os defensores de um novo modelo são tão cautelosos ao tratar do tema, afirmando que o debate em si não quer dizer que haverá progressos. Nesse sentido, Hacker (2003: 1) alertava que:

O crescente problema é trazer a reforma do Health Care de volta à agenda de políticas americanas após mais de uma década de negligência. E ainda, nada garante que este debate terminará de modo diverso das batalhas anteriores.

Essa retomada do debate sobre o funcionamento do Health Care era considerada prioridade pelos democratas. $\mathrm{O}$ trecho a seguir, retirado da Plataforma dos Democratas para as eleições presidenciais de 2008, demonstra o imperativo de se adotar mudanças significativas no excludente modelo do sistema de saúde adotado no país:

Se uma coisa surgiu através das audiências de base, foi que os Democratas estão unidos em torno de um compromisso de que todo homem, mulher e criança americanos estejam protegidos por um sistema de saúde abrangente e acessível. Em reunião após reunião, as pessoas expressavam

\footnotetext{
${ }^{4}$ Presidente Democrata dos Estados Unidos entre 1993 e 2001.
} 
reprovação moral pela crise do sistema de saúde que deixa milhões de americanos - inclusive 9 milhões de crianças - sem assistência de saúde e outros tantos milhões lutam para pagar os custos crescentes de um sistema de baixa qualidade. Metade de todas as falências pessoais na América são causadas por contas médicas. Nós gastamos mais em saúde do que qualquer outro país, mas estamos cotados em $47^{\circ}$ em expectativa de vida e $43^{\circ} \mathrm{em}$ mortalidade infantil. Nossa nação enfrenta epidemias de obesidade e doenças crônicas tão bem quanto à novas ameaças como a pandemia de gripe e o bioterrorismo. (DEMOCRATIC NATIONAL CONVENTION COMITEE, 2008: 9, tradução nossa).

A nova lei prevê que os planos privados não poderão discriminar os pacientes por doenças prévias à contratação dos serviços nem aumentar suas tarifas de modo arbitrário. Um dos pontos principais dentre as mudanças previstas é a criação de um sistema público de saúde, que supostamente concorreria com os planos privados, colaborando para redução dos custos. Um argumento em defesa de um plano público é a convicção de que o sistema dos planos privados nos Estados Unidos já não é mais competitivo e, portanto, tornou-se ineficiente.

O papel do plano governamental é conter os impactos adversos da concentração do mercado e, com isso, reduzir o crescimento dos gastos com o sistema de saúde [...] (Holahan e Blumberg, 2009: 1, tradução nossa).

Em contrapartida, é comum a alegação de que a criação de um plano público destruiria o atual sistema de planos privados, incapazes de competir com o Estado. Ainda, de acordo com estudo do Health Policy Center,

[...] os opositores temem que o plano público terá muitas vantagens inclusas que os planos privados serão incapazes de competir, eventualmente deixando o setor completamente nas mãos do governo, através da destruição do mercado competitivo de planos de saúde. Os apoiadores crêem que um plano público é a opção de último recurso em um sistema universal que cobriria os mais necessitados e os grupos de baixa renda (Holahan e Blumberg, 2009: 1, tradução nossa).

Para os republicanos é inadmissível a criação de um sistema público de saúde, taxando a reforma proposta por Obama de "socialista": além de inviabilizar os planos privados, constituiria uma ampliação dos poderes do governo e aumentaria também a corrupção, impondo custos em forma de impostos para os contribuintes que já pagam por seus planos. Segundo consta da Plataforma Republicana para as eleições presidenciais de 2008, o partido preza pela defesa da prática privada da medicina e se opõe a socialização da medicina na forma de um sistema de saúde universal de funcionamento estatal. Além disso, afirmam claramente:

\begin{abstract}
Nós não colocaremos o governo entre os pacientes e os provedores de planos de saúde. Nós não colocaremos o sistema em um caminho que aumente os poderes dos burocratas de Washington à custa dos pacientes. Nós não elevaremos impostos ao invés de reduzir os custos com o sistema de saúde Nós não substituiremos o sistema atual por ineficiência crescente, irracionalidade enlouquecedora e custos incontroláveis de um monopólio de Governo. (RNC, 2008: 37, tradução nossa).
\end{abstract}

As mudanças ocorridas na economia e sociedade americana ao longo das últimas décadas são apontadas como fatores que contribuem para a necessidade de reformar o sistema de saúde. Essas mudanças do perfil social da população e do emprego foram decisivas para tornar o sistema cada vez mais excludente e ineficiente. $\mathrm{O}$ mercado de trabalho já não é mais o mesmo da década de 1960, e nem as garantias que ele é capaz de oferecer aos trabalhadores.

Muitos americanos já trabalharam 40 horas semanais durante 40 anos para um único empregador que provinha pagamentos para sustentar a família, seguro saúde e previdência. Hoje, americanos trocam de emprego mais freqüentemente do que nunca e competem contra trabalhadores de todo o mundo por salários e benefícios. (Democratic National Convention Comitee, 2008: 9, tradução nossa).

Adequado a esta nova realidade, o novo sistema de saúde estende o atendimento a saúde para todos os americanos, por meio de um funcionamento similar ao do Medicare, propondo uma nova e efetiva estrutura de controle de custos dos serviços médicos para a melhora dos resultados do sistema. Para os defensores da proposta, garantir a acessibilidade e a qualidade do serviço para todos não é um absurdo político ou uma afronta aos americanos que pagam ou recebem serviço médico privado. A proposta de reforma do Health Care se encaixaria perfeitamente nos valores e crenças americanos e estaria assentada nos melhores elementos do atual sistema.

Para atingir os objetivos, o governo Obama fala em estabelecer um "Bill of Rights" dos pacientes, ou seja, um código de direito capaz de eliminar barreiras entre médicos e pacientes. Barreiras que, segundo o presidente, foram erguidas pelas seguradoras em seu domínio pleno do sistema de saúde. Além disso, de acordo com a organização Health Care 
for America Now ${ }^{5}$, o novo sistema de saúde deveria ser assentado em elementos centrais tais como: ser aberto a qualquer residente legal nos EUA sem boa cobertura trabalhista; exigir que os empregadores (e os trabalhadores autônomos) adquiram cobertura comparável ao sistema público para todos os seus trabalhadores ou paguem uma contribuição de $6 \%$ da folha de pagamento para financiar a cobertura do plano para todos os seus empregados.

$\mathrm{Na}$ medida em que a popularidade do presidente Barack Obama vem atingindo índices cada vez mais baixos - de acordo com o Instituto Gallup, nos primeiros dias de mandato a aprovação de Obama situava-se em $68 \%$, atingindo o pico de $69 \%$ no período de 22 a 24 de janeiro de 2009 e atingindo em torno de $50 \%$ a partir de meados de agosto de 2009 , período no qual se acirraram os debates sobre a reforma da saúde -, a polarização em torno da reforma da saúde cresce cada vez mais, conforme apontam alguns acontecimentos tais como as manifestações contrárias a Obama ocorridas em Washington nas primeiras semanas de setembro de 2009. Ainda segundo o mesmo instituto, o pior índice de aprovação do governo Obama foi 41\%, em outubro de 2010.

Nesse sentido, o trecho a seguir representa bem o contexto de polarização política em torno da reforma do sistema de saúde:

Uma reestruturação radical do Sistema de Saúde não seria sábia. Nós queremos que todos os americanos sejam aptos para escolher o melhor plano de saúde, hospital, e cobertura de acordo com suas necessidades. Acreditamos que a verdadeira reforma é melhorar o acesso ao plano de saúde, seu controle sobre o plano e sua capacidade de mantê-lo. (RNC, 2008: 38, tradução nossa).

Parece claro que as recentes discussões acerca da reforma do sistema público de saúde dos Estados Unidos estão tomando conta do dia a dia dos cidadãos estadunidenses e criaram um cenário de polarização dentro do contexto da cultura política pluralista dos Estados Unidos, levando ao extremo as tensões entre correntes liberais progressistas e conservadores de extrema direita.

Com base nesse contexto segue o segundo estágio desta análise, na tentativa de compreender melhor não apenas os pontos de vista, mas os interesses e implicações envolvidos no debate.

\section{Pluralismo e Polarização}

A eleição do primeiro presidente negro em um país que num passado não tão distante foi palco de

\footnotetext{
5 Disponível em http://healthcareforamericanow.org/. Acesso em $12 / 02 / 2011$
}

escancarada segregação racial parece não ter sido totalmente digerida pelos setores mais conservadores da sociedade estadunidense, mesmo após Obama ter conseguido seu segundo mandato nas urnas. As tensões acerca da eminência de mudanças no sistema de saúde dos Estados Unidos foram o estopim para que ataques e forte oposição tomassem proporções maiores já nos primeiros anos de governo, chegando a ponto de opositores e descontentes chamarem Obama de "nazista" - que, assim como a alcunha de "comunista", tem o objetivo de insultar o presidente - atestando a polarização e a tentativa de desqualificação do debate. Tal cenário levou o ex-presidente Jimmy Carter afirmar, em entrevista para a rede de TV NBC em 2009, que a maior parte dos ataques sofridos por Obama deve-se ao fato dele ser negro: ataques motivados por racismo. Por outro lado, a oposição alega que a declaração de Carter é uma simples tentativa de mudar o foco do debate.

Mas a radicalização que tomou conta dos debates em torno da reforma do sistema de saúde pública nos Estados Unidos vai muito além da questão racial: expõe uma disputa interna entre os setores que dividem a sociedade, opondo liberais com uma visão favorável a uma maior intervenção estatal no direcionamento de políticas públicas e conservadores que abominam qualquer participação do Estado em políticas voltadas para atender a população.

Analisar o que há por trás desse debate remete ao entendimento de como se deu a formação desses grupos que se polarizam através das disputas entre Democratas e Republicanos ao longo da história e, ainda, na disputa entre facções dentro dos próprios partidos. Assim, o preceito utilizado por Pecequilo (2005) ao analisar a Política Externa dos Estados Unidos se faz essencial também no debate proposto: em qualquer análise feita sobre qualquer contexto político e social, deve-se levar em consideração que o passado desse país é um guia que permite compreender o presente e projetar o futuro. A nosso ver, isso é fundamental para entender não só os direcionamentos da política externa estadunidense, como também sua política interna.

Ao abordar a política externa estadunidense, Pecequilo (2005) afirma um ponto essencial no entendimento do que vem ocorrendo nesse debate sobre as políticas de saúde:

[...] o passado é um patamar a partir do qual podemos refletir sobre a real natureza desse país e os caminhos que escolheu para si mesmo no mundo, de acordo não somente com seus interesses, mas em resposta às demandas de seus valores e de seu espírito como nação. (Pecequilo, 2005: 31). 
Torna-se, portanto, essencial analisar as recentes disputas em torno do futuro da saúde nos Estados Unidos partindo de um resgate histórico contemporâneo, mostrando sucintamente as diferentes visões e concepções presentes na sociedade considerada por muitos como a maior democracia do mundo.

Desde a independência, os Estados Unidos se intitulam como o "novo mundo" em contrapartida aos vícios europeus - leia-se, o absolutismo. Tidos como sinônimo de democracia e liberdade, relacionados às visões mais clássicas de individualismo e protestantismo, buscaram inculcar uma visão de si mesmo ao mundo e aos seus cidadãos, de que se imporiam aos demais países pela força da democracia. Criou-se a identidade de cada cidadão americano como sendo o representante de uma nação livre.

No período de 1776 até 1945, quando se deu a expansão do império, a justificativa das intervenções estadunidenses no exterior amparava-se no Destino Manifesto, centrado na premissa da democracia e liberdade. O Destino Manifesto pode ser caracterizado como uma ideologia que expressa a crença de que os Estados Unidos são o país eleito por deus para comandar o mundo. Logo, o imperialismo e o expansionismo estadunidense justificam-se como cumprimento da vontade divina. De acordo com os defensores do Manifesto, o expansionismo americano não é apenas bom, mas também óbvio e inevitável. Na definição de Pecequilo:

[...] o Destino Manifesto considerava que a expansão territorial representava um direito divino dos Estados Unidos de se espalhar por toda a América do Norte, com o apoio de Deus para a conquista, pois ela possibilitaria levar a liberdade e a democracia a locais em que ainda não existiam. Dotada de um sentido de propósito, a expansão territorial era racionalizada e explicada não por interesses materiais, mas pelo dever que os norte-americanos tinham de espalhar e afirmar seu espírito e visão, sintetizados no par democracia/ república. Aí, a combinação de cruzada e interesse, também característica de toda política externa norte-americana, encontrou sua primeira expressão. (Pecequilo, 2005: 57-58).

A construção das políticas tanto interna quanto externa dos Estados Unidos sempre foi baseada no imaginário e na ideologia pautada, sobretudo, pelo protestantismo sectário, de inspiração calvinista, com verdades absolutas e aparentes finalidades de controle e manipulação da opinião pública. Pecequilo (2005: 57) acrescenta ainda que o Destino Manifesto funcionava como uma justificativa e racionalização de interesses de poder por meio de uma retórica de destino, fé, escolha e crença, fundamentando a perseguição de objetivos e a expansão do regime político em termos não somente de interesses, mas da importância e necessidade da disseminação da experiência estadunidense por meio de ações concretas.

Qualquer ação ou intervenção dos Estados Unidos, por absurda que pareça, justificaria-se pela "vontade divina". A própria origem da sociedade estadunidense, que tem seu cerne na população de ascendência inglesa, branca e protestante, os chamados WASP (brancos, anglo-saxões e protestantes), ajuda a explicar tais aspectos descritos. Parsons (1993) salienta ainda que a nação foi consolidada durante sua independência política num contexto de uniformidade étnica e religiosa, suficiente tanto para tornar possível a solidariedade quanto para favorecer uma diversidade. No entanto, o núcleo central da sociedade estadunidense foi formado, como já pontuamos, pelo "branco, anglo-saxão e protestante - WASP ${ }^{6}$ ".

Outro ponto importante apontado por Parsons (1993) é o fato de que os negros, em sua maioria escravos, não estavam incluídos na nova sociedade. E, ainda, "[...] as minorias constituídas de católicos, holandeses e judeus eram tão pequenas que podiam ser consideradas estruturalmente desprezíveis". Com relação ao componente religioso, destaca-se uma diversidade interna. Constata que:

[...] apesar da relevante participação da Igreja Anglicana nas colônias, a maioria não anglicana mostrava compreensível relutância em apoiar a instituição anglicana, particularmente devido à óbvia relação entre esta e a Inglaterra. (Parsons, 1993).

Os WASP, núcleo dessa sociedade, conquistaram um elevado nível social, político e econômico principalmente após a Guerra de Secessão, período que configurou uma fase de grande prosperidade econômica. De acordo com Pecequilo (2005: 58-59), após a Guerra de Secessão os Estados Unidos finalizaram seu processo de consolidação sob a hegemonia do norte capitalista. A Guerra marcou o renascimento fortalecido da União e o restabelecimento do Estado mais centralizado no Executivo, garantindo que o país passasse a um novo estágio de desenvolvimento posterior à consolidação territorial.

Pecequilo (2005) afirma ainda que foi nesse período que se pôde observar o surgimento das

\footnotetext{
${ }^{6}$ Embora valores com liberdade e democracia sejam considerados como intrínsecos aos Estados Unidos, os WASP nutriram desde a formação da sociedade estadunidense um forte sentimento de racismo ante os imigrantes latinos e a população negra.
} 
grandes riquezas e das corporações norte-americanas, favorecidas por uma legislação pró-negócio e individualista, sendo também nesta época que os setores de comunicação e transportes passaram por uma ampla revolução e ampliação, com grande boom das ferrovias. Para Hobsbawm (2005), os Estados Unidos adentram o século XX como uma das maiores potências industriais do período.

A cultura política dos EUA, alicerçada nas necessidades básicas, tem seus valores e crenças compartilhadas e expressas nas suas instituições políticas: há, historicamente, uma clara preferência por um Estado pautado pela democracia, pelo livre mercado, pelas liberdades individuais, pelo direito de igualdade dos cidadãos perante a lei, pelo direito das minorias e pelo federalismo. Contudo, o sistema bipartidário estadunidense agrega interesses, formando amplas coligações de cunho religioso, econômico, educacional, profissional, sindicatos e outros grupos sociais (Wittkopf e McCormick, 2008). Embora estes sejam aspectos básicos do sistema, análises mais detidas de determinados fatos e aspectos da política dos Estados Unidos indicam que não parece ser generalização dizer que o mesmo se mostra cada vez mais polarizado, conforme pode ser observado através dos debates em torno da reforma do sistema de saúde.

O principal ponto que deve ser esclarecido se refere à composição político partidária, possibilitando entender quem são os Estados Unidos hoje e esclarecer o que está por trás do debate acerca da reforma do sistema de saúde. Conforme aponta Santos (2008), a história dos Estados Unidos costuma ser dividida didaticamente em três períodos distintos, referentes às configurações partidárias que se fizeram. A primeira fase diz respeito ao início da República que dá origem ao sistema partidário republicano/ federalista liderado por Thomas Jefferson e Alexander Hamilton; a segunda fase teria início com a fundação do Partido Democrata a partir dos republicanos jeffersonianos e; por fim, a consolidação do sistema partidário estadunidense em torno de Democratas e Republicanos.

Ao longo da história política dos Estados Unidos, questões relacionadas à escravidão e ao direcionamento da economia sempre estiveram presentes e, quase sempre, opuseram liberais e conservadores. De acordo com Santos (2008), a primeira fase da história americana, responsável pelo desaparecimento do partido Federalista, esteve pautada pela discussão de isenção de taxas e tarifas proposta pelo federalista Hamilton, além do pagamento de dívidas nacionais e a criação de um banco nacional; a segunda fase expõe questões relacionadas à economia e a escravidão, debate que opunha as regiões norte e sul dos Estados Unidos - norte de visão liberal e sul escravista.

Essa fase, conforme definida por Santos (2008), é importante para entender o realinhamento que ocorre no sistema partidário dos Estados Unidos no momento em que as forças políticas do norte se alinham em torno do Partido Republicano e o Partido Democrata se divide entre democratas do sul e do norte. Contudo, o essencial para este debate é o período posterior à Guerra Civil, que praticamente definiu o sistema partidário em torno de Republicanos e Democratas. Este período também marcou a divisão do Partido Democrata no tocante às políticas dos Estados Unidos. O grande debate se deu em função de temas relacionados aos direitos civis como a incorporação da população negra:

Após o trauma da guerra civil e a Reconstrução, o sistema partidário norte-americano se consolida em torno de dois grandes partidos, o Republicano, forte na região norte e praticamente inexistente no sul, e o Democrata, forte em ambas as regiões, mas dividido em algumas das principais matérias que definem a agenda pública do país. Assim é que de fins do século XIX até a década dos 30 do século $\mathrm{XX}$, a clivagem urbano rural contrapunha não só republicanos e democratas, mas no interior destes últimos, as bancadas representantes de estados mais e menos industrializados. A partir do "New Deal", a divisão entre os democratas adquire contorno mais nítido e se dá em função do tema dos direitos civis, isto é, da incorporação política e econômica da população afro-descendente. (Santos, 2008: 3).

Os diferentes interesses agregados nos partidos políticos americanos refletem-se nos direcionamentos tomados no Congresso, prevalecendo quase sempre a intenção das elites. Para Santos (2008), embora os Estados Unidos possam ser considerados o berço da cultura política pluralista, tal fato expôs a sociedade aos riscos da economia de mercado. O predomínio dos interesses das elites nos rumos políticos fez com que os Estados Unidos tivessem uma tímida distribuição de renda ao longo do tempo, aspecto que levou ao agravamento das situações de desigualdade social. Esta situação volta agora ao debate sob a forma do questionamento do modo de funcionamento do antigo sistema de saúde.

O Partido Republicano de Bush pai, Bush filho e Ronald Reagan, foi responsável pelas principais mudanças na história recente dos Estados Unidos, principalmente se tomarmos como ponto de partida o início da década de 1980. Entendendo as mudanças pró-mercado que os Republicanos impuseram na política e na economia dos Estados Unidos, compreende-se a posição do partido em relação à 
reforma no setor público de saúde. No entanto, é bom lembrar que não foram apenas os Republicanos que apoiaram tais reformas, mas também segmentos do partido Democrata que, orientados por uma linha liberal-conservadora, deram apoio às reformas neoliberais que se intensificaram no país cerca de 30 anos atrás.

Após os 12 anos de governo Republicano que marcaram o período 1980-1992, a eleição do Democrata Bill Clinton representou uma resposta à concentração de renda, à recessão, ao desemprego e à degradação ocorrida nos grandes centros urbanos durante o período anterior. Eleito sob o slogan Jobs! Jobs! Jobs! (Empregos! Empregos! Empregos!), o governo Clinton deparou-se com o desafio de implementar seu projeto de governo liberal após mais de uma década de aparelhamento conservador do Estado e sob o olhar desconfiado de um ator que adquiriu peso econômico e sobretudo político durante o governo dos Republicanos: o mercado financeiro.

A existência desse "novo" ator na arena política dos anos 1990 foi decisiva para dar um contorno conservador ao governo Clinton, especialmente no tocante à política econômica. A prioridade foi dada para redução do déficit orçamentário à custa dos gastos sociais, uma política no melhor estilo monetarista. Segundo o insuspeito Joseph Stiglitz (2003),

Era uma política arriscada, principalmente para um presidente que fora eleito com uma plataforma de "Empregos! Empregos! Empregos!". Aparentemente, sob a pressão da política e do tempo, os economistas de Clinton haviam subvertido meio século de pesquisa econômica. Durante décadas, os conservadores tentaram assassinar Keynes e seu apelo pela intervenção do governo em épocas de queda da atividade econômica. Aqui, em um curto espaço de tempo, nós, a turma de economistas de Clinton, os assim chamados Novos Democratas, realizamos o que os conservadores, por tão longo tempo, não conseguiram fazer; pois a economia se recuperou e o mérito foi atribuído à redução do déficit. (Stiglitz, 2003: 69).

Sob essa política ortodoxa, alinhada aos interesses do mercado financeiro, os Democratas foram acusados de quererem ser "mais realistas que o rei", deixando em segundo plano o investimento público e os gastos sociais. Somente com a recuperação econômica dos EUA ao longo da década foi possível ampliar o emprego, ainda assim, sob rígida disciplina fiscal e orçamentária.

O ponto central é que elementos como austeridade fiscal e rigidez orçamentária são aspectos que tomaram conta do cenário econômico norte americano e do mundo a partir do governo Reagan e se fixaram de tal forma, após recolocar os americanos no controle da economia mundial, que influenciaram inclusive políticos e partidos que historicamente defenderam uma bandeira mais progressista e com maior participação do poder público na economia.

No rastro da crise econômica dos anos 1970 e do colapso do modelo keynesiano, as medidas neoliberais foram adotadas visando primordialmente à estabilidade econômica a partir de um Estado forte no trato com a moeda e no enfrentamento dos sindicatos, mas passivo com relação às políticas sociais e intervenções na economia.

As principais medidas que nortearam o governo Reagan se deram em função do controle orçamentário em detrimento de políticas sociais e progressistas, tradicionalmente relacionadas aos Democratas. Qualquer alusão às políticas sociais fomentadas pelo Estado passava a ser atacada como política socialista ou comunista, discurso este já proferido pelos conservadores em décadas anteriores, mas que naquele momento se reforçava como nunca. A aplicação prática do neoliberalismo nos Estados Unidos na década de 1980 culminou, grosso modo, em uma nova política econômica orientada para o combate a inflação, a diminuição do déficit público, aumento da produtividade geral do sistema e maior liberdade aos agentes econômicos, mantida e aprofundada durante a década seguinte.

A implementação aguda do neoliberalismo nos Estados Unidos reforçou o setor privado e impulsionou ainda mais o desenvolvimento das empresas, principalmente do setor de serviços e finanças. O temor recente de setores privados, principalmente da saúde, é que o Estado venha a atuar mais diretamente nesses serviços e agir como um concorrente em uma esfera na qual não lhe cabe atuar.

Contudo, conforme aponta Anderson (1995), vale ressaltar que nos Estados Unidos não houve um Estado de bem-estar social ao estilo europeu. Se a prioridade neoliberal de Reagan na política externa foi um "keynesianismo militar disfarçado" visando à competição militar com a União Soviética como estratégia para quebrar a economia comunista do leste europeu, na política interna o governo de Reagan: “[...] reduziu impostos em favor dos ricos, elevou as taxas de juros e aplastou a única greve séria de sua gestão [...]" (Anderson, 1995: 10), a greve dos controladores de tráfego aéreo americanos em $1981^{7}$.

\footnotetext{
Mais de mil controladores aéreos entraram em greve naquele ano. O presidente Reagan ordenou que todos voltassem ao trabalho em 48 horas, ordem prontamente recusada pelos grevistas. Diante da situação, Reagan demitiu todos os controladores aéreos, fato este que inclusive lhe rendeu alta popularidade sendo fundamental para sua reeleição em 1984.
} 
O Democrata Bill Clinton, nos anos 1990, teve também como primeira prioridade ao assumir o governo reduzir o déficit orçamentário e adotar uma legislação contra a delinquência, seguindo o ideário do neoliberalismo (Anderson, 1995). Kowarick (2003) analisa o governo Clinton partindo da clássica divisão entre conservadores e liberais. Para os conservadores, as políticas públicas só serviriam para aumentar a delinquência e a ociosidade de pessoas que se encontram em precárias condições sociais por culpa própria. Do outro lado, os liberais apontam que não é o comportamento do indivíduo que leva a sua condição social, mas sim os processos estruturais mais amplos como a transformação da economia, da indústria, do mundo do trabalho e da ciência e tecnologia. Kowarick (2003) afirma que durante as décadas de 1960/70 houve uma hegemonia liberal progressista, superada pelo conservadorismo da década de 1980; nos anos 1990 com o governo Clinton, o autor afirma:

[...] com a administração Clinton, fundamentalmente no seu segundo mandato, com maioria parlamentar republicana, há uma aproximação dessas duas visões: as concepções liberais tradicionais que apregoavam a prerrogativa de direitos (entitlement) são solapadas pela noção de deveres e, em boa medida, passam também a responsabilizar os indivíduos por sua condição de vida [...] (Kowarick, 2003: 62).

Embora o aparentemente ambíguo governo Clinton tivesse obtido sucesso econômico que lhe rendeu alta popularidade, Pecequilo (2005) afirma que os erros táticos de seu pretenso sucessor e vice-presidente, Albert Arnold Al Gore, candidato democrata ao pleito no ano de 2000, bem como as falhas de seu próprio partido foram peça chave para a derrota nas urnas, levando as eleições a uma tremenda polarização e a consequiente vitória do candidato republicano George Walker Bush:

Polarizado, o pleito de 2000 revelou as contradições da maior democracia do mundo, as fragilidades de seu sistema político e um reajuste de forças de grupos internos, opondo moderados de ambos os partidos e os neoconservadores republicanos. Como resultado dessas tensões, presenciou-se a vitória neoconservadora, levando à implantação de uma série de reformas internas e externas, cujas consequências geram impactos diretos sobre a América e o mundo. (Pecequilo, 2005: 359).

O governo de George W. Bush foi bancado por maioria no Congresso e pôde levar a cabo uma política que, segundo Santos (2008), desafiou os próprios fundamentos da cultura política dos Estados Unidos, como com a aprovação do programa de redução de impostos, que comprometeu a capacidade do Estado em gerir políticas redistributivas. Santos (2008) afirma que o pluralismo sofreu um grande abalo durante o governo Bush, pois não favoreceu o cidadão de centro como normalmente se esperava.

O desafio apontado por Santos (2008) de que o próximo governo americano teria o desafio de redirecionar a situação deixada por Bush, convergindo para políticas voltadas para o cidadão médio no que se refere a temas como gasto social e tributação, bem como aproximar os partidos políticos como um todo da população de baixa renda, parece ter começado cedo e, ao contrário do imaginado, acirrou ainda mais a polarização ao invés de amenizá-la.

Os debates recentes acerca da reforma do sistema público de saúde dos Estados Unidos, a polarização entre conservadores de extrema direita e liberais viria à tona de forma mais incisiva pela primeira vez no novo governo eleito em 2008. A favor de uma ampla reforma no sistema, conforme proposta do governo democrata de Barack Obama, se encontravam os chamados Democratas liberais. Estes gostariam de uma reforma radical, mas aceitariam também um plano mais modesto desde que a mesma fosse aprovada no Congresso. De outro lado, Republicanos defendiam que a saúde fosse regulada apenas pelo mercado, e Democratas conservadores não aceitavam o custo da reforma estimado em 100 bilhões de dólares e exigiam que pequenos empresários não fossem obrigados a fornecer cobertura a seus funcionários.

Após um período de manifestações contra e a favor da proposta, além de acirrados debates, a reforma de saúde nos Estados Unidos acabou sendo aprovada no Senado em março de 2010. O projeto, que dependia de no mínimo 216 votos para ser aprovado acabou conquistando 219 votos, configurando talvez a maior vitória política do governo Obama até o momento. Contudo, uma observação merece destaque. Através de uma ordem executiva após a aprovação da proposta, Obama proibiu que verbas públicas fossem utilizadas para o aborto. Tal fato se deve a um acordo político com setores conservadores do próprio Partido Democrata que temiam a utilização de verbas do governo para tal finalidade.

Mesmo com a aprovação da reforma do sistema de saúde, o debate e a insatisfação dos republicanos ainda não terminou. Tramita na Flórida uma ação judicial que versa sobre a inconstitucionalidade da reforma, baseada no fato de que ela praticamente obriga o cidadão americano a ter cobertura de um plano de saúde, seja público ou privado. Essas e outras tentativas Republicanas de barrar a aplicação da lei seguem demonstrando os efeitos da acirrada polarização existente no Congresso e na sociedade 
estadunidense, que se choca imediatamente com a cultura política pluralista ao torná-la excludente e, portanto, menos plural.

Tal polarização entre conservadores e liberais já aponta para a confirmação de uma pesquisa apontada por Santos (2008) que demonstra que as bancadas Democrata e Republicana no Congresso tem correspondência com os anseios das classes média e alta e menos afinidade com as classes baixas, que são as que mais crescem nos Estados Unidos, justamente por conta das assimetrias cada vez maiores que o sistema vem gerando, promovendo um empobrecimento nacional e uma estrutura socioeconômica similar a do Brasil. A proposta apresentada pelo senador Democrata Max Baucus, que faz concessões a demandas republicanas como veto a atendimento a imigrantes ilegais, proibição de financiamento de abortos e não criação de um plano de saúde administrado pelo governo para concorrer com as seguradoras pode vir a prosperar no Congresso, mesmo não contando com o apoio republicano.

A questão é que esse debate já tornou explícitas as diferenças que existem dentro da sociedade dos EUA. O ápice se deu quando o deputado Republicano Joe Wilson esbravejou de forma grosseira durante discurso do presidente Obama, que argumentando que o mesmo mentia quando afirmava que a reforma não iria cobrir imigrantes ilegais. Em seguida, a declaração de Jimmy Carter afirmando que os ataques a Obama se devem ao fato dele ser negro, polarizou ainda mais as disputas entre liberais e conservadores. Protestos e ataques passaram a virar uma constante sendo inclusive incentivadas por jornalistas de direita como Glenn Black da Fox News e o radialista Rush Limbaugh que chegou a dizer que na América de Obama são os meninos brancos que apanham, enquanto os negros aplaudem. O crescimento de agremiações de ultra-direita como o Tea Party também é um indicativo da intensificação da polarização do debate político.

Republicanos, contudo, acusaram os democratas de quererem desviar o foco da questão da reforma da saúde, mas não se atentam para um detalhe explicitado pela cronista de política do The New York Times, Maurren Dowd, que afirma que o congressista Joe Wilson pertence aos Filhos dos Veteranos Confederados e que, em 2000, liderou uma campanha para que a bandeira dos Confederados tremulasse no topo da Câmara dos Representantes da Carolina do Sul, além de denunciar por calúnia uma mulher negra que declarou ser filha de Strom Thurmond, candidato segregacionista a presidência em 1948 (a veracidade da mulher negra foi posteriormente comprovada). Maureen Dowd afirma ter ouvido do deputado a expressão: "Você mente, rapaz!". De acordo com a cronista, o termo "rapaz" era utilizado pelos brancos sulistas em relação aos negros, possuindo forte conotação pejorativa racista.

Chama a atenção a forma discreta como o presidente Obama tratou do incidente, que reflete a polarização existente no país não apenas na política, como foi dada ênfase neste texto, mas também a polarização social, alimentada pelo pensamento segregacionista que se fortalece nos Estados Unidos e transparece a dificuldade dos setores conservadores em aceitar o fato de que o país é hoje (e já há muito tempo) uma nação multicultural, cuja cultura plural é histórica, e não um país homogêneo de puritanos que desembarcaram do Mayflower. O crescimento da pobreza e da exclusão nas grandes cidades dos Estados Unidos, a imigração de trabalhadores ilegais, a segregação racial acobertada, são elementos que se somam ao quadro de polarização que a elite WASP prefere expulsar ou ignorar, acreditando que os EUA ainda são um país de brancos, proprietários e protestantes. Para essa fração da sociedade (que se configura quase como uma casta), a eleição de Obama foi uma piada de mau gosto inaceitável, uma perversão dos costumes e da tradição estadunidense.

\section{Considerações Finais}

Mesmo com o setor mais conservador da sociedade estadunidense - os WASP - não aceitando a eleição de Obama, chegando ao ponto de acirrarem os ataques contra o presidente, não se pode resumir os ataques sofrido pelo governo Democrata apenas ao fato de o presidente ser negro, embora este seja um fator de relevância. A grande questão se dá em torno do temor que o governo Obama despertou no setor privado de gerenciamento de saúde nos Estados Unidos.

Aliás, não apenas a ascensão de Obama causou temor, mas também a mudança do perfil nacional dos Estados Unidos com o crescimento hispânico, tema caro para Samuel Huntington, cientista político estadunidense que num artigo intitulado "The Hispanic Challenge", publicado em 2004, afirmava com forte teor xenófobo que a identidade de seu país estava sendo desafiada pelas forças da globalização, chegando ao ponto de dizer que os hispânicos, principalmente os imigrantes mexicanos, configuram uma ameaça para a cultura e os valores estadunidenses.

No momento em que os Estados Unidos se deparam com a possibilidade de uma volta ao passado no melhor estilo intervencionista, houve um temor por parte do setor privado de que o Estado deixasse de servir aos seus interesses para se tornar um concorrente, mesmo que isso viesse a beneficiar a maior parte da população. O grande temor da extrema direita é que o Estado passe, mesmo que timidamente, 
a gerir políticas públicas fazendo com que a população dependa menos dos seguros privados de saúde e comece a fazer valer mais o valor de seus impostos, passando a ter como direito um sistema público de saúde. As acusações desencontradas que partem de setores conservadores contra a reforma no sistema de saúde de que Obama seria "comunista", revelam não só a polarização como a pobreza (e o absurdo) a que chegou o debate.

Mesmo com a aprovação da proposta do novo sistema de saúde dos Estados Unidos na Câmara dos Representantes em março de 2010, fica latente a crescente polarização existente na política e na sociedade, suscitadas pelo debate em questão. Assim, espera-se que esta contribuição permita, ao menos, compreender o contexto político e histórico no qual se deu a proposta de reforma do sistema de saúde estadunidense, e como se compõem as forças que debateram o projeto. Realizado este objetivo, torna-se mais claro o entendimento do verdadeiro alcance da reforma do Health Care, que se coloca agora muito além de simples mudanças (por mais complexas que sejam) no funcionamento do sistema de saúde dos Estados Unidos.

\section{Referências}

Anderson, Perry. 1995. Balanço do neoliberalismo. In E. Sader e P. Gentili (orgs.), Pós-neoliberalismo: as políticas sociais e o Estado democrático. Rio de Janeiro: Paz e Terra, p. 09-23.

Democratic National Convention Comitee. 2008. The 2008 Democratic National Platform: Renewing America's Promise. Washington: Democratic National Comitee.

Gallup Institute. 2009. Nearly 30\% of Insured have Government Plans, Up from '08. Disponível em: $<$ http://www.gallup.com/poll/121970/NearlyInsured-Government-Coverage-2008.aspx>. Acesso em: 18 set. 2012.

Hacker, Jacob. 2007. Health Care for America: a Proposal for guaranteed, affordable Health Care for all Americans building on Medicare and employmentbased insurance. Washington: Economic Policy Center Briefing Paper.

Hobsbawm, Eric. 2005. A era dos Impérios. São Paulo: Ed. Paz e Terra.
Holahan, John. 2009. and Blumberg, Linda. Is the Public Plan Option a Necessary Part of the Reform? In Health Policy Center. The Urban Institute Health Policy Center. Disponível em: <www.healthpolicycenter. org >. Acesso em: 18 set. 2012.

Huntington, Samuel. 2004. The Hispanic Challenge. Disponível em: <http://cyber.law. harvard.edu/blogs/gems/culturalagency 1/ SamuelHuntingtonTheHispanicC.pdf $>$. Acesso em: 27 fev. 2013.

Kowarick, Lúcio. 2003. Sobre a vulnerabilidade socioeconômica e civil: Estados Unidos, França e Brasil. Revista brasileira de Ciências Sociais, 18(51): 61-86. http://dx.doi.org/10.1590/ S0102-69092003000100006

Organización Panamericana de la Salud - OPS. 2003. Perfil de Sistemas y Servicios de Salud: Estados Unidos de América. Programa de Organización y Gestión de Sistemas y Servicios de Salud, División de Sistemas y Servicios de Salud.

Parsons, Talcott. 1993. Cidadania Plena para o Americano Negro: um problema sociológico. Revista Brasileira de Ciências Sociais, (23). Disponível em: <http:// www.anpocs.org.br/portal/publicacoes/rbcs_00_22/ rbcs22_03.htm>. Acesso em: 26 fev. 2013.

Pecequilo, Cristina. 2005. A Política Externa dos Estados Unidos: continuidade ou mudanças? Porto Alegre: Editora da UFRGS.

Republican National Convention - RNC. 2008. The 2008 Republican Party Platform.

Santos, Fabiano. 2008. Estados Unidos: Dimensões histórica, política e cultural. Rio de Janeiro, III Conferencia Nacional de Política Externa e Política Internacional.

Stiglitz, Joseph. 2003. Os exuberantes anos 90: Uma nova interpretação da década mais próspera da história. São Paulo: Companhia das Letras.

The White House. 2010. Remarks by the president on the affordable care act and the new patient's bill of rights. Washington. Disponível em: <http://www. whitehouse.gov/the-press-office/remarks-presidentaffordable-care-act-and-new-patients-bill-rights $>$. Acesso em: 07 fev. 2013.

U'S Census Bureau. 2001. Health Insurance Coverage: 2000. Washington: U.S. Department of Commerce Economics and Statistics Administration.

Wittkopf, Eugene e McCormick, James. 2008. The domestic sources of American foreign policy. New York: Rowman \& Littlefield Publishers. 